\title{
Desempenho de ovinos recebendo suplementos ou mantidos exclusivamente em pastagem de azevém (Lolium multiflorum Lam.)
}

\section{Luís Henrique Ebling Farinatti ${ }^{1}$, Marta Gomes da Rocha ${ }^{2}$, César Henrique Espírito Candal Poli $^{3}$, Cléber Cassol Pires ${ }^{2}$, Luciana Pötter ${ }^{1}$, José Henrique Sousa da Silva ${ }^{2}$}

\author{
1 Programa de Pós-Graduação em Zootecnia - UFSM. \\ 2 Departamento de Zootecnia - UFSM. \\ ${ }^{3}$ Embrapa.
}

RESUMO - Avaliou-se o desempenho de ovelhas com cria e, posteriormente, das cordeiras recém-desmamadas, mantidas exclusivamente em pastagem de azevém (Lolium multiflorum Lam) ou recebendo grão de milho ou farelo de soja na proporção de $1 \%$ PV da unidade ovina (ovelha + cordeira). Foram avaliados os seguintes parâmetros: ganho médio diário, ganho de peso vivo por hectare e carga animal. Na pastagem, as avaliações realizadas foram: massa, perdas e oferta de forragem, altura da pastagem, oferta de lâminas de folhas verdes, taxa de acúmulo de matéria seca, produção total de forragem, teor de proteína bruta e digestibilidade in vitro da matéria orgânica da forragem aparentemente consumida. A carga animal não foi afetada com a suplementação aos animais. Ovelhas suplementadas com farelo de sojam no período de 17/09 a 08/10, apresentaram maior ganho médio diário que os animais não-suplementados. Ovelhas tiveram ganho diário médio decrescente no decorrer do período de pastejo, com redução de $3,4 \mathrm{~g}$ a cada dia de pastejo. A produção de $\mathrm{PV} /$ ha foi maior quando os animais receberam suplementação com farelo de soja. A estrutura da pastagem sofreu modificações no decorrer do ciclo do azevém, independentemente do fornecimento do suplemento aos animais.

Palavras-chave: carga animal, cordeira, grão de milho, ovelha, farelo de soja

\section{Performance of sheep fed different supplements or only Italian ryegrass (Lolium multiflorum L.) pasture}

\begin{abstract}
The objective of this trial was to evaluate production of nursing ewes and yearling female lambs grazing annual ryegrass pasture (Lolium multiflorum Lam) supplemented or not with corn grain or soybean meal. Supplements were fed to animals in a quantity equivalent to $1 \%$ of sheep unit (ewe + lamb) body weight. The following variables were investigated: average daily gain, body weight gain per hectare, and stocking rate while for ryegrass pasture the following measurements were taken: forage mass, losses, and allowance, pasture height, green leaf allowance, forage mass accumulation rate, total forage production, crude protein content, and in vitro digestibility of hand plucking material. Supplementation did not significantly affect the stocking rate in this trial. Female lambs supplemented with soybean meal had higher average daily gain than those not supplemented that lost $3.4 \mathrm{~g}$ daily on pasture only. Body weight gain per hectare was highest by feeding soybean meal to sheep. The sward structure changed during pasture cycle independently of treatment effects.
\end{abstract}

Key Words: corn grain, ewe, female lamb, soybean meal, stocking rate

\section{Introdução}

O Rio Grande do Sul possui o maior rebanho ovino do Brasil, com aproximadamente cinco milhões de cabeças (ANUALPEC, 2005). A ovinocultura gaúcha volta-se, cada vez mais, para a produção de cordeiros jovens para abate. Para suprir a demanda de carne ovina, é necessária a intensificação desta atividade, pelo uso de sistemas alimentares também intensivos e econômicos, proporcionando o melhoramento da alimentação dos animais por meio de pastagens cultivadas, confinamento e suplementação.
O lento desenvolvimento das cordeiras é um dos aspectos limitantes da produção ovina do Rio Grande do Sul, cuja base forrageira é a pastagem natural. No período de junho a setembro, quando há limitação na produção e qualidade das pastagens nativas, ocorre redução no desenvolvimento dos animais recém-nascidos e na produção de leite das ovelhas. O cultivo de pastagens de inverno, como o azevém anual (Lolium multiflorum Lam.), de maior importância em áreas cultivadas no Sul do país, pode melhorar a oferta e a qualidade de forragem, favorecendo o desenvolvimento dos ovinos nesta estação. 
A intensificação dos sistemas de produção tem favorecido o uso de suplementos para animais em pastejo. A prática de suplementação é utilizada tanto na tentativa de suprir as deficiências nutricionais da pastagem, proporcionando o balanceamento da dieta dos animais, como para redução do risco ocasionado pela flutuação da produção de matéria seca da pastagem. Quando há suplementação, os animais podem substituir parte do consumo de forragem pelo de suplemento, com conseqüências na produção e na estrutura da pastagem. Conforme Genro et al. (2001), a suplementação aos animais em pastejo pode interferir na taxa de acúmulo de matéria seca e na oferta de lâminas foliares. Em pastagem de baixa qualidade, o suplemento protéico pode aumentar o consumo de forragem, enquanto o suplemento energético em pastagem de alta qualidade pode reduzir esse consumo (Clanton et al., 1971). As características das pastagens, quando os animais são suplementados, devem ser estudadas com critérios rigorosos para que seja melhor entendida a relação planta-animal-suplemento e produtividade dos animais.

As taxas reprodutivas do rebanho devem ser elevadas e a idade de acasalamento das cordeiras de reposição, a menor possível para que exista adequada produção de cordeiros. Restrições alimentares, além de afetarem negativamente o desenvolvimento animal, diminuem a capacidade reprodutiva do rebanho, pois as fêmeas só atingem peso mínimo para o acasalamento com idade elevada (Figueiró, 1986). Com utilização de pastagens com maior oferta de matéria seca e melhor qualidade que as pastagens naturais, como o azevém, a velocidade de crescimento das cordeiras é aumentada, podendo ser reduzida sua idade de encarneiramento.

Este trabalho foi realizado com o objetivo de avaliar, a partir das características quantitativas e qualitativas, uma pastagem de azevém (L. multiflorum Lam.) sob pastejo de ovinos recebendo ou não suplementação e o desenvolvimento de ovelhas com cria e de cordeiras desmamadas recebendo suplementação com grão de milho ou farelo de soja.

\section{Material e Métodos}

O experimento foi desenvolvido na Universidade Federal de Santa Maria, Santa Maria, RS, situada na Depressão Central do Rio Grande do Sul, com altitude de 95 m, 2943' de latitude Sul e $53^{\circ} 42^{\prime}$ 'de longitude oeste. O clima da região é subtropical úmido (Cfa), conforme a classificação de Köeppen (Moreno, 1961).

A área experimental foi composta por 2,47 ha, com seis subdivisões cultivadas com azevém anual (Lolium multiflorum Lam). Os tratamentos foram: 'grão de milho'ovelhas com cria ao pé, em pastagem de azevém, recebendo grão de milho; 'farelo de soja' - ovelhas com cria ao pé, em pastagem de azevém, recebendo farelo de soja; 'azevém' ovelhas com cria ao pé em pastagem de azevém, não suplementadas. Após a desmama, os tratamentos foram avaliados nas cordeiras.

A semeadura da pastagem foi realizada de 10 a 15 de maio de 2000 , utilizando-se $50 \mathrm{~kg} /$ ha de sementes de azevém, e o experimento foi conduzido até outubro de 2000. Foram aplicados $200 \mathrm{~kg} /$ ha de NPK (05-20-20) e, como adubação de cobertura, efetuaram-se cinco aplicações de nitrogênio $(45,0 ; 22,5 ; 22,5 ; 22,5 ; 45,0 \mathrm{~kg} / \mathrm{ha}$, em 17/06, 03/07, 06/08, 28/08 e 28/09 de 2000).

Os animais permaneciam na pastagem das 7 às $19 \mathrm{~h}$ e, no período noturno, eram excluídos, permanecendo em mangueiras contíguas a pastagem, onde recebiam os suplementos - grão de milho ( $8,1 \%$ de PB e $81,7 \%$ de NDT) moído a $5 \mathrm{~mm}$ ou farelo de soja $(37,0 \%$ de $\mathrm{PB}$ e $82,5 \%$ de NDT) - na proporção de $1 \%$ do peso total da unidade ovina, formada pela ovelha e sua cria. Os cochos para suplementação ficaram abrigados da chuva e as sobras, em razão da pequena quantidade, foram desprezadas.

O sistema de pastejo foi contínuo, com taxa de lotação variável. $\mathrm{O}$ ajuste de carga foi realizado visando manter massa de forragem (MF) de $1.200 \mathrm{~kg} / \mathrm{ha}$ de MS, avaliada a cada 21 dias pelo método de dupla amostragem em cada uma das repetições, sendo 15 estimativas visuais e três cortes. Para cálculo da MF disponível, foi adotada a equação proposta por Gardner (1986).

A altura da pastagem foi medida com o auxílio de uma régua graduada, considerando-se o ponto de curvatura das lâminas foliares e a altura da superfície da pastagem.

A taxa de acúmulo diária de MS do azevém foi avaliada a cada 21 dias, utilizando-se duas gaiolas de exclusão ao pastejo, e estimada pela equação descrita por Campbell (1966). A partir dos resultados de MF, de carga animal e de taxa de acúmulo de MS, foi calculada a oferta de forragem, em $\mathrm{kg}$ de MS/100 kg de PV. A produção total de MS do azevém foi estimada pelo somatório das produções dos períodos (taxa de acumulação diária x número de dias do período) mais a MF inicial.

A determinação da relação lâmina foliar:colmo das amostras coletadas da pastagem foi realizada pela separação manual dos componentes colmo e lâmina foliar. Após secagem em estufa de ventilação forçada por 72 horas, foram obtidos os percentuais de lâmina foliar, colmo e material morto de cada amostra (peso seco de cada componente, dividido pelo peso total da amostra). Considerando-se os 
resultados de produção de lâmina foliar e carga animal, foi calculada a oferta de lâminas de folhas verdes, em kg de MS de lâminas de folhas verdes por $100 \mathrm{~kg}$ de PV.

No início do experimento, foram demarcados dez pontos amostrais em cada repetição, para determinação das perdas de forragem. Em cada avaliação, ao lado de cada ponto amostral, foi colocado um quadrado $\left(0,01 \mathrm{~m}^{2}\right)$, recolhendo-se o material nele constante, constituído por material morto ou danificado, considerado não-aproveitável pelo animal. Após cada coleta, as amostras foram secas em estufa e pesadas posteriormente. Os pesos secos das amostras da avaliação de perdas de forragem foram divididos pela carga animal do período correspondente e o resultado das perdas, expresso em percentual do $\mathrm{PV}$.

A estimativa da qualidade da forragem consumida foi realizada por meio da análise das amostras obtidas, utilizando-se a técnica de simulação manual do pastejo (Euclides et al., 1992), pela observação dos animais-teste. Foram determinadas a MS total, a MM, a PB (AOAC, 1984) e a digestibilidade in vitro da MO (Tilley \& Terry, 1963).

Ovelhas e cordeiras foram tatuadas ao nascimento e, posteriormente, marcadas com brinco na orelha direita. As ovelhas e cordeiras serviram como animais-teste nos dois períodos iniciais, entre 14/07 e 26/08. As cordeiras foram desmamadas em $26 / 08$, quando os animais apresentavam aproximadamente 60 dias de idade. Nos períodos de 27/08 a 17/09; 18/09 a 08/10 e 09 a 29/10, foram utilizadas apenas as cordeiras desmamadas como animais-teste. Os animais foram agrupados nos tratamentos conforme a idade das ovelhas e o período de nascimento das cordeiras.

As pesagens dos animais foram realizadas em intervalos de 21 dias, após jejum prévio de 12 horas. O ganho de PV foi calculado pela diferença de peso dos animais nas datas de pesagem e o ganho médio diário (GMD), pela divisão do ganho de PV pelo número de dias do período. $\mathrm{O}$ ganho de $\mathrm{PV} /$ ha/tratamento foi calculado pela soma do ganho de PV dos animais-teste com o ganho dos animais reguladores, corrigido pelo NDT consumido pelos animais-teste. A carga animal (CA) por período foi calculada por meio da soma do peso médio dos animais-teste mais o peso dos animais reguladores, multiplicado pelo número de dias que permaneceram na pastagem. O produto foi dividido pelo número de dias do período de pastejo e expresso em $\mathrm{kg} / \mathrm{ha}$ de PV.

O consumo estimado de matéria seca por período foi obtido subtraindo-se a forragem disponível no final do período experimental mais as perdas de forragem ocorridas ao longo do período de pastejo da produção total estimada de MS/ha. Dividindo o consumo estimado de MS/ha pela carga animal média, obteve-se o consumo estimado de MS, em porcentagem do $\mathrm{PV}$.

O delineamento experimental adotado foi o inteiramente casualizado, com parcelas subdivididas no tempo e duas repetições de área (potreiros). As variáveis estudadas foram submetidas à análise de variância dos dados e ao teste F a 5\% de significância e, quando detectadas diferenças entre tratamentos, aplicou-se o teste Tukey. As variáveis foram submetidas à análise de regressão para os dias de pastejo, com ajuste do modelo polinomial até terceira ordem. As análises foram feitas utilizando-se procedimento GLM(General Linear Model) do programa estatístico SAS versão 6.08 (SAS, 1996).

\section{Resultados e Discussão}

A massa de forragem, a oferta de lâmina foliares verdes, a oferta de forragem, a altura da pastagem, a taxa de acúmulo de matéria seca, a produção total de forragem e as perdas de forragem da pastagem de azevém não diferiram $(\mathrm{P}>0,05)$ entre os tratamentos (Tabela 1).

A massa de forragem foi de $1221 \pm 187,61 \mathrm{~kg} / \mathrm{ha} \mathrm{de} \mathrm{MS}$ e apresentou regressão quadrática ( $\mathrm{Y}=789,32+18,29 \mathrm{x}-$ $\left.0,1476 \mathrm{x}^{2}, \mathrm{R}^{2}=37,7 \%, \mathrm{P}=0,005\right)$. Conforme Hafley (1996), a utilização de pastagem de azevém perene com massa de forragem em torno de $1.200 \mathrm{~kg} / \mathrm{ha}$ de MS permite a seletividade do material ofertado pelos animais em pastejo. A disponibilidade de forragem requerida para o máximo desempenho animal, em espécies temperadas, situa-se entre 1.200 e $1.600 \mathrm{~kg} / \mathrm{ha}$ de MS (Mott, 1981). A produção total de forragem foi de $6.225 \pm 414,85 \mathrm{~kg} / \mathrm{ha} \mathrm{de}$ MS, considerando-se a média dos três tratamentos $(\mathrm{P}>0,05)$.

Considerando-se os valores médios das ofertas de lâmina foliares verdes e de forragem (Tabela 1), nota-se que não houve restrição aparente ao consumo de forragem pelos animais em pastejo. Fischer et al. (1997) observaram, em pastagem de azevém utilizada por ovinos, que não houve limitação ao consumo, com ofertas de 8 e $12 \%$ de forragem.

A altura da pastagem está relacionada à massa de lâminas foliares verdes e de colmo e indica a biomassa presente. Penning et al. (1994) constataram não haver limitação ao consumo por ovinos em pastejo quando a altura média da pastagem de azevém perene foi superior a $10 \mathrm{~cm}$. Para o manejo correto da pastagem e as tomadas de decisões sobre ajustes na carga animal, a altura da pastagem é um parâmetro de utilização mais fácil que a massa de forragem. Fluxos de crescimento e consumo apresentaram valores máximos com altura de manejo da pastagem de azevém entre 10 e $15 \mathrm{~cm}$ (Pontes et al., 2004). 
Tabela 1 - Massa de forragem (MF, kg/ha de MS), oferta de lâminas foliares verdes (OLFV, kg MS/100kg de PV), oferta de forragem (OF, $\mathrm{kg}$ de $\mathrm{MS} / 100 \mathrm{~kg}$ de $\mathrm{PV})$, altura da pastagem $(\mathrm{AL}, \mathrm{cm})$, taxa diária de acúmulo de matéria seca (TA, $\mathrm{kg} / \mathrm{ha}$ de $\mathrm{MS}$ ), produção total de forragem (PTF, kg/ha de MS) e perdas de forragem (PF, \% do PV) em pastagem de azevém (L. multiflorum Lam) sob pastejo de ovinos, com ou sem suplementação (grão de milho ou farelo de soja)

Table 1 - Herbage mass (HM, kg/ha of DM), green leaf allowance (GLA, kg DM/100kg of BW), herbage allowance (HA, $\mathrm{kg} D M / 100 \mathrm{~kg}$ of BW), pasture height $(\mathrm{PH}, \mathrm{cm})$, accumulation rate (AR, $\mathrm{kg} D \mathrm{M} / \mathrm{ha}$ /day), total herbage yield (TPH, $\mathrm{kg} / \mathrm{ha}$ of DM) and forage losses (FL, \% of BW) for sheep grazing annual ryegrass (L. multiflorum Lam) pasture with or without supplementation (corn grain or soybean meal)

\begin{tabular}{|c|c|c|c|c|c|c|c|}
\hline \multirow[b]{2}{*}{$\begin{array}{l}\text { Tratamento } \\
\text { Treatment }\end{array}$} & \multicolumn{7}{|c|}{$\begin{array}{l}\text { Características da pastagem } \\
\text { Sward characteristics }\end{array}$} \\
\hline & $\begin{array}{l}\text { MF } \\
H M\end{array}$ & $\begin{array}{c}\text { OLFV } \\
G L A\end{array}$ & $\begin{array}{l}\mathrm{OF} \\
H A\end{array}$ & $\begin{array}{l}\mathrm{AL} \\
P H\end{array}$ & $\begin{array}{l}\mathrm{T} \mathrm{A} \\
A R\end{array}$ & $\begin{array}{l}\text { P T F } \\
T P H\end{array}$ & $\mathrm{PF}$ \\
\hline $\begin{array}{l}\text { Grão de milho } \\
\text { Grain of corn }\end{array}$ & 1.213 & 8,2 & 16,4 & 11,9 & 44,0 & 5.873 & 0,89 \\
\hline $\begin{array}{l}\text { Farelo de soja } \\
\text { Soybean meal }\end{array}$ & 1.170 & 7,4 & 13,7 & 12,4 & 49,1 & 6.672 & 0,83 \\
\hline $\begin{array}{l}\text { Azevém } \\
\text { Ryegrass annual }\end{array}$ & 1.279 & 8,3 & 16,4 & 12,0 & 45,9 & 6.131 & 0,84 \\
\hline $\begin{array}{l}\text { Média } \\
\text { Mean }\end{array}$ & 1.221 & 8,0 & 15,5 & 12,1 & 46,3 & 6.225 & 0,85 \\
\hline
\end{tabular}

$\mathrm{P}>0,05$.

A taxa de acúmulo de forragem foi de $46,3 \pm 27,38 \mathrm{~kg} / \mathrm{ha}$ $\operatorname{de} \mathrm{MS} / \mathrm{dia}\left(\mathrm{Y}=172,59-9,95 \mathrm{x}+0,19 \mathrm{x}^{2}-0,001 \mathrm{x}^{3}, \mathrm{R}^{2}=62,3 \%\right.$, $\mathrm{P}=0,0001)$ e está na faixa observada por Rocha et al. (2001), em pastagem de aveia mais azevém sob pastejo contínuo. As condições climáticas foram extremamente desfavoráveis durante o mês de agosto, quando foi verificada a menor taxa de acúmulo $(3,0 \mathrm{~kg} / \mathrm{ha} / \mathrm{dia}$ de $\mathrm{MS})$. Nesta ocasião, a temperatura média foi de $14,9^{\circ} \mathrm{C}$, a precipitação pluviométrica de 127,4 mm, a insolação média de 5,8 horas/dia e ainda houve a formação de geadas em 15 dias e a presença de nevoeiro em 16 dias. As taxas de acúmulo resultaram em produção média total de $6.225 \mathrm{~kg} / \mathrm{ha}$ de MS. Valores próximos a $10.000 \mathrm{~kg} / \mathrm{ha}$ de MS, para misturas de cereais de inverno, foram relatados por Lesama \& Moojen (1999).

As perdas de forragem, $0,85 \%$ do $\mathrm{PV}$, em média, representaram pequeno percentual da oferta de forragem, com média de $15,5 \%$ entre os três tratamentos em todo o período experimental, sendo representadas por uma regressão quadrática, $\mathrm{Y}=1,4-0,03 \mathrm{x}+0,00027 \mathrm{x}^{2}, \mathrm{R}^{2}=45,3 \%$, $\mathrm{P}=0,00007$, com menor percentual de perdas no $56^{\circ} \mathrm{o}$ dia de uso da pastagem $(12,4 \%$ de oferta de lâminas foliares verdes), ocasião em que as cordeiras foram desmamadas. Perdas de forragem apresentaram correlação negativa $(0,5)$ com oferta de lâminas de folhas verdes $(\mathrm{P}=0,05)$. Cecato et al. (2001) mencionaram que, entre os fatores que influenciam a taxa de senescência e as perdas de forragem, estão o manejo da pastagem, a estação de crescimento, a utilização da pastagem realizada sob cortes ou pastejo, a adubação e o sistema de pastejo. Frizzo et al. (2001) observaram, em aveia e azevém, perdas médias de forragem de 1,98\% do PV, independentemente da variação na carga animal durante o período de uso da pastagem. Mudanças na carga animal, proporcionada pelo uso de suplementos - em torno de 32,47 e 38,95\% para grão de milho e farelo de soja, respectivamente - não contribuíram para mudanças nas perdas de forragem. O efeito da carga animal sobre a taxa de senescência da forrageira, porém, foi observado por Birchan \& Hodgson (1983), que registraram aumento linear da taxa de senescência com cargas menores.

A suplementação com grão de milho ou farelo de soja não alterou $(\mathrm{P}>0,05)$ o teor de nitrogênio da forragem consumida pelos animais em pastejo, observando-se, para esta variável, melhor ajuste do modelo quadrático (Figura 1), com valor máximo de $\mathrm{PB}$ colhida no 71ํㅡㅁ dia de utilização da pastagem. Os animais, mesmo no final do ciclo do azevém, colheram uma forragem com elevado teor de PB, sempre superior às exigências para os ganhos (NRC, 1985). Segundo Bryant et al. (1968), a qualidade da forragem ingerida decresce se a oferta de forragem reduzir a oportunidade de pastejo seletivo pelos animais.

Os valores de DIVMO na forragem aparentemente consumida diferiram $(\mathrm{P}<0,05)$ quando os animais foram suplementados ou não, correspondendo, respectivamente, a 76,95; 72,09; e 69,63\% para os tratamentos grão de milho, farelo de soja e azevém. Animais sob suplementação com grão de milho ou farelo de soja colheram forragem com maior DIVMO que os não suplementados, não havendo diferença entre os suplementos $(\mathrm{P}>0,05)$. A porcentagem de DIVMO se ajustou melhor ao modelo quadrático, com maior valor no 45 o dia de pastejo $\left(Y=71,23-0,273 \mathrm{x}+0,003 \mathrm{x}^{2}, \mathrm{R}^{2}=41,8 \%\right.$, $\mathrm{P}=0,03)$. A média de DIVMO (72,8\%) demonstra que os animais colheram forragem de alta qualidade sob as condições de manejo da pastagem de azevém e que a DIVMO se correlaciona positivamente com o ganho médio diário das cordeiras $(0,4)$ e negativamente com a porcentagem de perdas $(-0,4)$. 
A suplementação não proporcionou alterações $(\mathrm{P}>0,05)$ no GMD das ovelhas, observando-se diferença $(\mathrm{P}<0,05)$ apenas no período de $17 / 09$ a $08 / 10$, em que houve ganhos de 0,$171 ; 0,152 ;$ e $0,109 \mathrm{~kg} /$ dia nos tratamentos com farelo de soja, grão de milho e sem suplementação, respectivamente. O tratamento com suplementação protéica promoveu ganho superior $(\mathrm{P}<0,05)$ ao da pastagem exclusiva, não diferindo $(\mathrm{P}>0,05)$ da suplementação energética. $\mathrm{O}$ teor de $\mathrm{PB}$ da forragem, 22\% (Figura 1), neste período, não foi limitante ao desempenho animal (NRC, 1985), mas o valor da oferta de folhas verdes, de $5,5 \mathrm{~kg}$ folhas verdes $/ 100 \mathrm{~kg}$ de $\mathrm{PV}$, e a quantidade de proteína consumida na pastagem foram, provavelmente, os fatores que interferiram no efeito da suplementação sobre o ganho individual. O GMD das cordeiras apresentou regressão significativa, com melhor ajuste do modelo linear (Figura 2), e foi decrescente no decorrer do período de pastejo, com redução de $3,4 \mathrm{~g}$ a cada dia de utilização da pastagem.

Apesar de estarem em lactação, as ovelhas ganharam peso, $0,186 \mathrm{~kg} / \mathrm{dia}$, em média. Esses dados discordam dos resultados encontrados por Carvalho et al. (1999), quando verificaram que as ovelhas praticamente mantiveram peso durante a lactação em pastagem de aveia (A. strigosa) + azevém (L. multiforum) + trevo vesiculoso (Trifolium vesiculosum) e quando foram alimentadas com silagem + concentrado.

Neste estudo, as ovelhas sofreram redução no peso vivo no período pós-parto de 59,02 para $52,07 \mathrm{~kg}$, peso medido no início do período experimental. Esse peso foi recuperado durante a permanência dos animais na pastagem, com os animais pesando $60,37 \mathrm{~kg}$ por ocasião da desmama

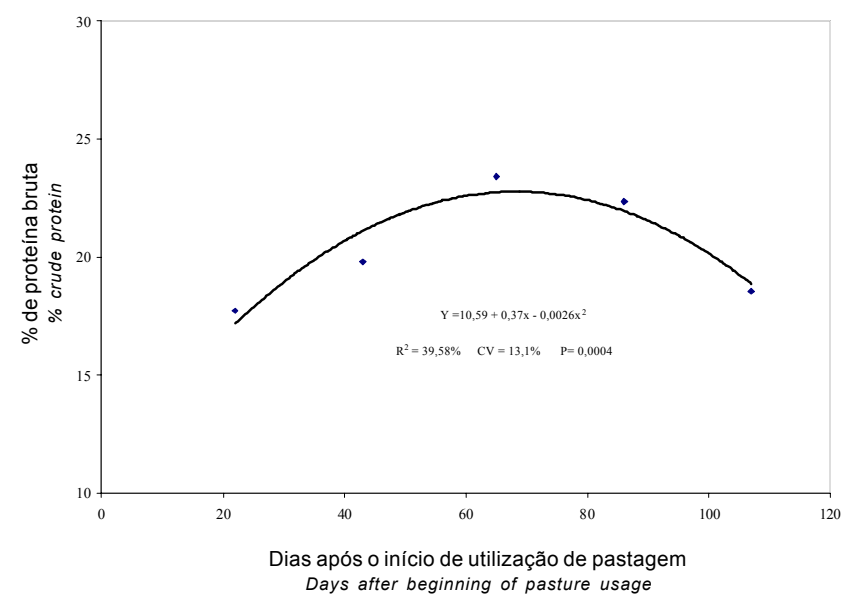

Figura 1 - Proteína bruta da forragem aparentemente consumida da pastagem de azevém (L. multiflorum Lam.) sob pastejo por ovinos sob suplementação ou não com grão de milho ou farelo de soja.

Figure 1 - Contents of CP of hand plucking annual ryegrass pasturewith (corn grain or soybean meal) or without supplementation. das cordeiras. O uso exclusivo da pastagem de azevém foi adequado para o desenvolvimento produtivo de ovelhas, com idade de 1 a 3 anos e cria ao pé. Bianchi et al. (2001) observaram redução no peso médio do pós-parto ao desmame em ovelhas de 3 anos com cria em campo nativo com suplementado ou não com $300 \mathrm{~g}$ de cevada/ovelha/dia.

Na média do período total de pastejo, o ganho médio diário das cordeiras foi semelhante $(\mathrm{P}>0,05)$, de 0,177 ; 0,$201 ; \mathrm{e} 0,216 \mathrm{~kg}$ para animais sob suplementação com grão de milho, farelo de soja ou sem suplementação, respectivamente. Os valores de PB da forragem aparentemente consumida pelos animais variaram de 17 a 23\% (Figura 1) e, associados à oferta de forragem, que não restringiu o consumo, certamente contribuíram para que, na média dos períodos, a suplementação não interferisse no ganho individual. Rocha et al. (1999) concluíram que é possível obter elevados ganhos de peso de cordeiras ao pé da mãe, quando submetidas exclusivamente à pastagem de azevém, sem necessidade de suplementação. Entretanto, em experimento com ovelhas e cordeiros pastejando uma gramínea tropical, estrela branca (Cynodon plectostachyus), a suplementação favoreceu o ganho de peso dos cordeiros, com $147 \mathrm{~g}$ a mais por dia em relação à não-suplementação (Neres et al., 2001).

Os consumos estimados de matéria seca da gramínea pelos animais foram de 5,38\% (pastagem exclusiva), 4,38\% (suplementação com farelo de soja) e 3,51\% do PV (suplementação com milho). Quando o consumo de matéria seca da pastagem $(4,38 \%)$ foi somado ao de suplemento (1\%), animais que receberam suplementação com farelo de soja tiveram consumo similar ao daqueles sem suplementação,

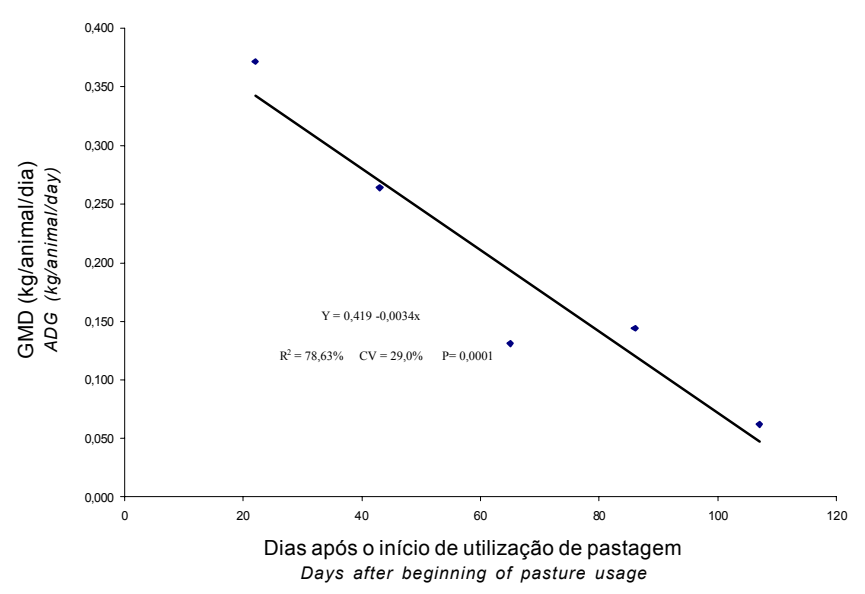

Figura 2 - Ganho médio diário $(\mathrm{kg})$ de cordeiras em pastagem de azevém (L. multiflorum Lam.) sob pastejo por ovinos sob suplementação ou não com grão de milho ou farelo de soja.

Figure 2 - Average daily gain $(\mathrm{kg})$ of lambs grazing annual ryegrass (L. multiflorum Lam) pasture with (corn grain or soybean meal) or without supplementation. 
Tabela 2 - Ganho médio de peso vivo por área (kg/ha de PV) de ovinos em pastagem de azevém suplementada ou não com grão de milho ou farelo de soja

Table 2 - Mean body weight gain (BWG/ha) of sheep grazing annual ryegrass pasture with (corn grain or soybean meal) or without supplementation

\begin{tabular}{|c|c|c|c|c|c|c|}
\hline \multirow[t]{2}{*}{$\begin{array}{l}\text { Tratamento } \\
\text { Treatment }\end{array}$} & \multicolumn{5}{|c|}{$\begin{array}{l}\text { Período } \\
\text { Period }\end{array}$} & \multirow[b]{2}{*}{ Total } \\
\hline & $\begin{array}{l}14 / 07 \\
05 / 08\end{array}$ & $\begin{array}{l}05 / 08 \\
26 / 08\end{array}$ & $\begin{array}{l}26 / 08 \\
17 / 09\end{array}$ & $\begin{array}{l}17 / 09 \\
08 / 10\end{array}$ & $\begin{array}{l}08 / 10 \\
29 / 10\end{array}$ & \\
\hline $\begin{array}{l}\text { Grão de milho } \\
\text { Corn grain }\end{array}$ & 207,3 & 89,2 & 57,9 & 56,1 & 6,1 & $416,7 \mathrm{ab}$ \\
\hline $\begin{array}{l}\text { Farelo de soja } \\
\text { Soybean meal }\end{array}$ & 266,3 & 94,2 & 59,8 & 89,6 & 16,4 & $526,3 \mathrm{a}$ \\
\hline $\begin{array}{l}\text { Azevém } \\
\text { Annual ryegrass }\end{array}$ & 129,7 & 87,5 & 28,5 & 39,5 & 25,7 & $310,9 b$ \\
\hline
\end{tabular}

Médias seguidas de letras diferentes na mesma coluna, diferem $(P<0,05)$ pelo teste Tukey.

Means followed by different letters in the same column differ $(P<0.05)$ by Tukey test.

com desempenho individual também semelhante. Para os animais sob suplementação com grão de milho, quando somados os consumos de suplemento (1\%) e de forragem $(3,51 \%)$, o valor foi inferior ao estimado para animais sem suplementação $(5,38 \%)$, sem resultar, no entanto, em ganho individual distinto $(\mathrm{P}>0,05)$.

A suplementação possibilitou redução no consumo de forragem, com eficiências do uso da pastagem de 10,08 e $11,35 \mathrm{~kg}$ de MS/kg PV produzido por hectare para os tratamentos com farelo de soja e grão de milho, respectivamente. Quando os animais permaneceram exclusivamente em pastagem, a eficiência de utilização da forragem foi de $15,81 \mathrm{~kg}$ de MS por kg de PV produzido por hectare, comprovando o efeito substitutivo decorrente do consumo do suplemento, que foi mais acentuado quando houve suplementação com farelo de soja. Canto et al. (1999) observaram, em pastagem de azevém e trevo branco, eficiências de uso da matéria seca de 28, 17 e 10,50 kg de MS/kg de PV em disponibilidades de 1.320 e $2.410 \mathrm{~kg} / \mathrm{ha}$ de MS, respectivamente.

Houve diferença no GPV $/$ ha $(\mathrm{P}<0,05)$ entre os tratamentos (Tabela 2), de modo que a suplementação com farelo de soja diferiu do uso exclusivo da pastagem, mas foi semelhante $(\mathrm{P}>0,05)$ à suplementação com grão de milho. A produção de peso vivo/hectare, em ovinos, foi semelhante à registrada com bezerras de 8 a 10 meses de idade, em pastagem de azevém e aveia suplementada com energia, $540 \mathrm{~kg} d e \mathrm{PV} / \mathrm{ha}$, ou exclusivamente em pastagem, $359 \mathrm{~kg}$ de $\mathrm{PV} / \mathrm{ha}$, até o final de setembro (Rocha et al., 2003). Com o mesmo potencial de produção, o valor do produto comercializável de cada espécie determina a eficiência econômica da utilização das pastagens no período de inverno/primavera.

O ganho de peso vivo/ha proporcionado pela suplementação com farelo de soja foi $69 \%$ superior ao obtido com uso exclusivo da pastagem e não diferiu $(\mathrm{P}>0,05)$ daquele proporcionado pela suplementação com grão de milho. Animais sob suplementação reduziram o consumo de forragem, possibilitando maior carga animal por hectare e, mesmo com ganho individual semelhante, esse efeito resultou em maior ganho por área. Os valores de GPV/ha diminuíram com o decorrer do ciclo do azevém, como efeito da menor carga animal e do menor desempenho individual no final do ciclo da pastagem, em decorrência das mudanças na estrutura da pastagem.

O ganho de peso por área dos animais sob suplementação em relação aos não suplementados resultou em consumos de 9,71 kg de milho e 3,99 kg de farelo de soja por quilo de PV ganho, demostrando maior eficiência do uso do farelo de soja como suplemento em pastagem de azevém sob pastejo por ovinos. Em estudo com bovinos, Rocha et al. (2003) utilizaram, em média, 7,4 kg de grão de sorgo como suplemento para cada quilo adicional de ganho de PV/ha.

A produção de quilos de cordeira por ovelha foi de $30,53 \mathrm{~kg}$ para animais exclusivamente em pastagem, enquanto, para ovelhas e cordeiras sob suplementação com farelo de soja e grão de milho, as produções foram de 24,78 e $22,75 \mathrm{~kg}(\mathrm{P}>0,05)$, respectivamente, demonstrando, em pastagem de clima temperado, a importância do aleitamento e da dependência da cordeira em relação ao leite materno, não sendo verificada influência do suplemento na produção, em kg, de cordeiras desmamadas/ovelha.

O desmame foi realizado quando as cordeiras tinham idade próxima aos 60 dias e peso médio de $21,9 \mathrm{~kg}$. No final do ciclo do azevém, as cordeiras possuíam aproximadamente 120 dias de idade e 28,9 kg PV. Souza \& Espíndola (1999) observaram peso final semelhante em cordeiros sob suplementação com feno de leucena (Leucena leucocephala (Lam) de Witt) em capim-buffel(Cenchrus ciliaris), aos 168 dias de idade dos animais. Ribeiro et al. (2000) constataram, 
em cordeiros inteiros ou castrados em pastagem de coastcross-1 (Cynodon dactylon (L.) Pers), aos três e aos seis meses de idade, $\mathrm{PV}$ semelhantes aos pesos no desmame e final deste experimento.

O peso vivo das cordeiras no final do ciclo do azevém representou $83 \%$ do peso mínimo para o encarneiramento de fêmeas das raças utilizadas, que seria próximo a $35 \mathrm{~kg}$, considerando-se que deveriam atingir, nesta ocasião, $65 \%$ de seu peso adulto. Para serem encarneiradas em fevereiro, as cordeiras necessitariam de ganho de peso próximo a 70 gramas/dia durante os meses de novembro a janeiro.

Não houve diferença $(\mathrm{P}>0,05)$ entre os tratamentos para os valores da carga animal, em kg/ha de PV, que apresentaram regressão significativa para o período de pastejo, ajustando-se melhor à equação cúbica ( $\mathrm{Y}=2115,93-$ $\left.83,15 \mathrm{x}+1,62 \mathrm{x}^{2}-0,009 \mathrm{x}^{3}, \mathrm{R}^{2}=25,9 \%, \mathrm{P}=0,01\right)$. A suplementação, no entanto, possibilitou aumentos de $15,86 \%$ (grão de milho) e $21,52 \%$ (farelo de soja) na carga animal utilizada em relação ao uso exclusivo da pastagem. A possibilidade de maior suporte de carga animal com o uso de suplementos demonstra o efeito substitutivo causado principalmente pelo farelo de soja.

A carga animal média nos tratamentos com suplementação de $1.010,8 \mathrm{~kg} / \mathrm{ha}$ de $\mathrm{PV}$, foi semelhante à de $1.152,75 \mathrm{~kg} / \mathrm{ha}$ de PV de ovinos verificada por Canto et al. (1994), com diferentes massas de forragem, em pastagem de azevém e trevo branco. Esta carga também é similar à obtida com bovinos (1120 kg/ha de PV) recebendo suplementação energética durante todo o período de produção da pastagem de aveia e azevém (Rocha et al., 2003).

\section{Conclusões}

Ovinos mantidos em pastagem de azevém, com oferta não limitante de lâminas foliares verdes $(8 \mathrm{~kg} \mathrm{MS} / 100 \mathrm{~kg}$ de PV), colheram forragem com alto teor de proteína bruta durante todo o ciclo da pastagem e seu ganho individual não foi afetado pela suplementação com farelo de soja ou grão de milho.

A produção e a estrutura da pastagem de azevém não foram modificadas quando os ovinos permaneceram exclusivamente em pastagem ou sob suplementação com grão de milho ou farelo de soja.

A suplementação de ovinos em pastagem de azevém com farelo de soja proporcionou maior ganho de peso vivo por área e melhor eficiência de utilização da pastagem (kg de MS da pastagem/kg de PV).

\section{Literatura Citada}

ANUALPEC. Anuário da pecuária brasileira. São Paulo: Instituto FNP Consultoria \& Comércio, 2005. 340p.

ASSOCIATION OF OFFICIAL ANALYTICAL CHEMISTS - AOAC. Official methods of analysis. 14.ed. Washington, D.C.: 1984. $1141 \mathrm{p}$.

BIANCHI, G.; BURGUENO, J.; ABELLA, D.F. et al. Post weaning feeding manegement and performance of merino ewes grazing on natural and improved pastures at mating season. Ciência Rural, v.31, n.1, p.105-110, 2001.

BIRCHAM, J.S.; HODGSON, J. The influence of sward condition on rates of herbage growth and senecence in mixed swards under continuous stocking management. Grass and Forage Science, v.38, p.323-331, 1983.

BRYANT, H.T.; BLASER, R.E.; HAMMES, R.C. et al. Effect of grazing management on animal and area output. In: ANNUAL MEETING OF THE AMERICAN SOCIETY OF ANIMAL SCIENCE, 1968. Anais... Beltsville, 1968. p.153-158.

CAMPBELL, A.G. Grazed pastures parameters: I. Pasture dry matter production and availability in a stocking rate grazing management experiment with dairy cows. Journal Agricultural Science, v.67, n.2, p.211-216, 1966.

CANTO, M.W. Produção de cordeiros em pastagem de azevém(Lolium multiflorum Lam) + trevo branco (Trifolium repens L.) submetida a níveis de resíduos de forragem. Santa Maria: Universidade Federal de Santa Maria, 1994. 194p. Dissertação (Mestrado em Zootecnia)- Universidade Federal de Santa Maria, 1994.

CANTO, M.W.; MOOJEN, E.L.; CARVALHO, P.C.F. et al. Produção de cordeiros em pastagem de azevém e trevo branco sob diferentes níveis de resíduos de forragem. Pesquisa Agropecuária Brasileira, v.34, n.2, p.309-316, 1999.

CARVAlHO, S.; PIRES, C.C.; BERNARDES, R.A.C. et al. Desempenho e produção de lã de ovelhas lactantes e ganho de peso e características da carcaça dos cordeiros. Ciência Rural, v.29, n.1, p.149-153, 1999.

CECATO, U.; CASTRO, C.R.C.; CANTO, M.W.C. et al. Perdas de forragem em capim-Tanzânia (Panicum maximum Jacq. Cv. Tanzania-1) manejado sob diferentes alturas de pastejo. Revista Brasileira de Zootecnia, v.30, n.2, p.295-301, 2001.

CLANTON, D.C.; HILDERBARAND, R.L.; JONES, L.E. Supplements for yearling cattle on summer range. Journal of Range Management, v.24, n.3, p.105-109, 1971.

EUCLIDES, V.P.B; MACEDO, M.C.M.; OLIVEIRA, M.P. Avaliação de diferentes métodos de amostragem sob pastejo. Revista Brasileira de Zootecnia, v.21, n.4, p.691-702, 1992.

FIGUEIRO, P.R.P. Manejo nutricional para produção de ovinos tipo carne e tipo 1ã. In: SIMPOSIO PARANAENSE DE OVInOCultura, 3., 1986, Guarapuava. Anais... Londrina, IAPAR, 1986. p.37-45.

FISCHER. V.; DESWYSEN A.G.; DÉSPRES, E.H. et al. Efeito da pressão de pastejo sobre o comportamento ingestivo e o consumo voluntário de ovinos em pastagem. Revista Brasileira de Zootecnia, v.26, n.5, p.1025-1031, 1997

FRIZZO, A.; ROCHA, M.G.; FREITAS, M.R. Effect of energetic supplementation in an oat and italian ryegrass pasture under continuous grazing In: INTERNATIONAL GRASSLAND CONGRESS, 19., 2001, São Paulo. Proceedings... São Paulo: Brazilian Society of Animal Husbandry, 2001. p.85-87.

GARDNER, A.L. Técnicas de pesquisa em pastagens e aplicabilidade de resultados em sistemas de produção. Brasília: IICA/EMBRAPA-CNPGL, 1986. 197p. IICA, Série publicações Miscelâneas, 634. 
GENRO, T.C.M.; GONÇALVES, E.N.; ROCHA, M.G. et al. Efeito da suplementação energética de terneiras em pastagem de milheto (Pennisetum americanum) sobre a freqüência de pastejo e morfogênese vegetal. In: REUNION LATINO AMERICANA DE PRODUCCION ANIMAL, 17., 2001, Havana. Memorias... Havana, Cuba, SOFTCAL, 2001. p.2726-2728.

HAFLEY, J.L. Comparison of Marshall and Surrey ryegrass for continuous and rotational grazing. Journal of Animal Science, v.74, p.2269-2275, 1996.

LESAMA, M.F.; MOOJEN, E.L. Produção animal em gramíneas de estação fria com fertilização nitrogenada ou associada com leguminosa, com ou sem fertilização nitrogenada. Ciência Rural, v.32, n.3, p. 303-308, 1999.

Moreno, J.A. Clima do Rio Grande do Sul. Porto Alegre: Secretaria da Agricultura, 42p. 1961.

MOTT, G.O. Potential productivity of temperate and tropicall grassland systems. In: INTERNATIONAL GRASSLAND CONGRESS, 1960, England. Anais... England: 1981. v.8. p.606.

NATIONAL RESEARCH COUNCIL - NRC. Nutrient requirements of sheep. Washington, D.C.: National Academy Press, 1985. 99p.

NERES, M.A.; GARCIA, C.A.; MONTEIRO, A. L. et al. Níveis de fenos de alfafa e forma física da ração no desempenho de cordeiros em creep feeding. Revista Brasileira de Zootecnia, v.30, n.3, p.941-947, 2001.

PENNING, P.D.; PARSONS, A.J.; ORR, R.J. Intake and behaviour responses by sheep to changes in sward characteristics under rotational grazing. Grass and Forage Science, v.49, p.476486, 1994

PONTES, L.S.; CARVALHO, P.C.F.; NABINGER, C. et al. Fluxo de biomassa em pastagem de azevém anual (Lolium multiflorum Lam.) manejada em diferentes alturas. Revista Brasileira de Zootecnia, v.33, n.3, p.529-537, 2004.
RIBEIRO, E.L.A; ROCHA, M.A; MIZUBUTI, I. et al. Ganho de peso e componentes de peso vivo em borregos Ile de France inteiros ou castrados e Hampishare Down castrados abatidos aos doze meses de idade. Ciência Rural, v.30, n.2, p.333-336, 2000.

ROCHA, M.G.; PIRES, C.C.; POLI C.H.E.C. et al. Efeito da suplementação energética no desenvolvimento de ovelhas e cordeiras sob pastagem de azevém In: REUNIÃO ANUAL DA SOCIEDADE BRASILEIRA DE ZOOTECNIA, 37., 1999, Viçosa, MG. Anais... Viçosa, MG: Sociedade Brasileira de Zootecnia, 1999. p.81.

ROCHA, M.G.; MONTAGNER, D.B.; FREITAS, F.K. et al. Dinâmica de uma pastagem de aveia (Avena strigosa) e azevém (Lolium multiflorum) em diferentes sistemas intensivos de utilização. In: REUNIÓN LATINOAMERICANA DE PRODUCCIÓN ANIMAL, 2001, Havana. Anais... Havana: SOFTAL, 2001. p. 2013-15.

ROCHA, M.G.; RESTle, J.; PILAU, A. et al. Produção animal e retorno econômico da suplementação em pastagem de aveia e azevém. Ciência Rural, v.33, n.3, p.85-93, 2003.

STATISTICAL ANALYSES SYSTEM - SAS. SAS Language reference. Version 6, Cary: 1996. 1014p.

SOUZA A.A.; ESPINDOLA, B.G. Efeito da suplementação com feno de leucena (Leucena leucocephala (Lam) de Wit) durante a estação seca sobre o desenvolvimento ponderal de ovinos. Revista Brasileira de Zootecnia, v.28, n.6, p.1424-1429, 1999.

TILLEY, J.M.A.; TERRY, R.A.A. Two stage technique for the "in vitro" digestion of forage crops. Journal of British Grassland Society, v.18, n.2, p.104-111, 1963.

Recebido: $13 / 04 / 05$ Aprovado:08/08/05 